\title{
Avaliação de genótipos de arroz sob o efeito fitotóxico interativo dos ácidos acético, propiônico e butírico
}

\section{Rice genotypes evaluate under the interactive phytotoxic effect of acetic, propionic and butyric acids}

\author{
Mauricio Marini Köpp ${ }^{1 *}$; Viviane Köpp da Luz²; Jefferson Luiz \\ Meirelles Coimbra ${ }^{3}$; Rogério Oliveira de Sousa ${ }^{4}$; Antonio Costa de Oliveira ${ }^{5}$
}

\begin{abstract}
Resumo
O objetivo do trabalho foi avaliar o desenvolvimento de 20 genótipos de arroz aos ácidos acético, propiônico e butírico, compostos fitotóxicos produzidos em solos de deficiente drenagem e alto teor de matéria orgânica. $\mathrm{O}$ trabalho foi executado em sistema de hidroponia com 4 doses $(0 ; 3 ; 6$ e 9 $\mathrm{mM}$ ) dos ácidos na relação 6:3:1 acético, propiônico e butírico respectivamente. O delineamento utilizado foi blocos casualizados com 3 repetições num esquema fatorial. As variáveis mensuradas foram comprimento de raízes (CR) e parte aérea (CPA), número de raízes (NR) e massa seca de raízes (MSR) e parte aérea (MSPA). Os dados relativos às variáveis mensuradas foram submetidos à análise de variância em um modelo fatorial (4x20), considerando dose e genótipo como fatores fixos e ajuste de regressões. A variável CR foi a mais afetada pelo ácido e as regressões estabelecidas para as variáveis CR e CPA revelaram 2 genótipos com estabilidade de crescimento radicular e 3 com estabilidade de crescimento de parte aérea frente ao estresse por ácidos orgânicos. Genótipos de maior rusticidade e desenvolvidas para sistema de irrigação por inundação se mostraram mais tolerântes ao ácido.

Palavras-chave: Estresse abiótico, ácidos orgânicos, Oryza sativa, recursos genéticos
\end{abstract}

\begin{abstract}
The objective of this work was to evaluate the development of 20 rice genotypes to acetic, pripionic and butyric acid, a phytotoxic compounds produced in low drainage soils with high organic matter content. This work was performed in hydroponics with four acid doses $(0 ; 3 ; 6$ e $9 \mathrm{mM})$ and 6:3:1 relationship acetic, propionic and butyric respectively. A factorial random block design with three replications were performed. The variables measured were root (CR) and shoot (CPA) length, number of roots (NR) and root (MSR) and shoot (MSPA) dry matter. The data relative to the measured variables were subjected to an analysis of variance in a factorial model $(4 \times 20)$ and regression fitting, considering dose and genotype as fixed factors. Significance for the interaction (genotype vs. dose) was found only for CR and CPA. The variable $\mathrm{CR}$ was the most influenced by the acid and the regression stablished for the variables CR and CPA revealed 2 genotypes with root length stability and 3 with shoot length stability front to organic acid stress. Genotypes with higher rusticity and developed for irrigated systems were more tolerant.

Key words: Abiotic stress, organic acids, Oryza sativa, genetic resources
\end{abstract}

\footnotetext{
${ }_{1}^{1}$ Pesquisador, Embrapa Pecuária Sul, BR-153, KM-603, CEP 96401-970, Bagé, RS. E-mail: mauricio.kopp@cppsul.embrapa.br

2 Discente, Universidade Federal de Pelotas, UFPel, Centro de Genômica e Fitomelhoramento, Campus Universitário, s/nº , C. P. 354, CEP 96010-900, Pelotas, RS. E-mail: vivikp05@yahoo.com.br

3 Prof. da Universidade do Estado de Santa Catarina, UDESC, Instituto de Melhoramento e Genética, Av. Luiz de Camões, 2090, CEP 88520-000, Lages, SC. E-mail: coimbrajefferson@cav.udesc.br

${ }^{4}$ Prof. da UFPel, Dept ${ }^{\mathrm{o}}$ de Solos, Pelotas, RS. E-mail: rosousa@ufpel.edu.br

${ }^{5}$ Prof. da UFPel, Centro de Genômica e Fitomelhoramento, Pelotas, RS. E-mail: acostol@terra.com.br

* Autor para correspondência
} 


\section{Introdução}

O arroz é um dos três principais cereais em importância econômica e social a nível mundial. O Brasil é o principal produtor fora do continente asiático com 1,86\% da produção mundial, e o Rio Grande do Sul foi responsável por aproximadamente $70 \%$ desta produção na safra 2011 (CONAB, 2011). Além destes fatores, o arroz é hoje estudado de maneira mais avançada devido a seu papel como genoma modelo para outras espécies (DEVOS; GALE, 2000), (IRGSP, 2005). O melhoramento genético desta espécie permitiu incremento significativo na sua produtividade, no entanto este incremento está apresentando ganhos cada vez mais lentos e dispendiosos. Assim, o estudo de caracteres de interesse como qualidade industrial do produto, resistência a pragas e moléstias (estresses bióticos), tolerância a frio, estiagens, encharcamento, toxidez por alumínio ou ácidos orgânicos (estresses abióticos), se torna fundamental para melhoria da eficiência de ganho genético da espécie (JANICK, 2001).

A Região Sul do Brasil apresenta uma área de 6,8 milhões de hectares constituída por solos hidromórficos, representando $20 \%$ da área total do estado do Rio Grande do Sul (PINTO; LAUS; PAULETTO, 2004). Nestes solos, a maioria das espécies cultivadas tem seu desenvolvimento e produção prejudicados devido à má drenagem natural que provoca um ambiente anaeróbico (PONNAMPERUMA, 1972). Como a cultura do arroz irrigado tem como característica principal a manutenção de uma lâmina de água sobre o solo durante a maior parte do seu desenvolvimento, o $\mathrm{O}_{2}$ presente é consumido e os microorganismos anaeróbios passam a atuar produzindo elevada quantidade de produtos intermediários fitotóxicos, dentre os quais destacam-se os ácidos orgânicos alifáticos de baixo peso molecular (acético, propiônico e butírico), que ocorrem na faixa de concentração de 0,1 a $14 \mathrm{mM}$ e relação de 6:3:1 respectivamente (GOTOH; ONIKURA, 1971; CAMARGO; SANTOS; ROSSIELO,
1993; ANGELES; JOHNSON; BURESH, 2005; BOHNEN et al., 2005; JOHNSON et al., 2006; KOPP et al., 2009a; KOPP et al., 2010).

Quanto maior o tamanho da cadeia de carbonos maior é sua fitotoxidez (RAO; MIKKELSEN, 1977a; ANGELES; JOHNSON; BURESH, 2005). Kopp et al. (2007a) demonstraram que uma concentração de $10 \mathrm{mM}$ de cada ácido reduziu o crescimento radicular de arroz em torno de $44 \%$ com ácido acético, 70 \% propiônico e $77 \%$ para o butírico, demonstrando a maior fitotoxidade do ácido butírico.

Os sistemas de semeadura direta e cultivo mínimo de arroz irrigado são muito utilizados, pois proporcionam aumento da produtividade e lucratividade associada à elevada redução dos impactos ambientais advindos do cultivo convencional (GOMES; MAGALHÃES JUNIOR, 2004). Um dos princípios fundamentais destes sistemas de semeadura se refere a manutenção e, em alguns casos, até adição de resíduos vegetais sob a superfície do solo, ocasionando maior produção de ácidos orgânicos de cadeia curta, que podem estar limitando o crescimento e a produtividade do arroz cultivado nesses sistemas (JOHNSON et al., 2006; KOPP et al., 2009b; KOPP et al., 2010).

Os efeitos relativos a presença destes ácidos orgânicos no solo são mais acentuados nas fases iniciais de desenvolvimento do arroz, ocorrendo menor germinação, menor crescimento radicular e menor peso e altura de plântulas (SOUSA; BORTOLON, 2002). Efeitos sobre outras fases de desenvolvimento como menor afilhamento, menor absorção de nutrientes e menor rendimento de grãos podem ser observadas quando as plantas estiverem submetidas a maior tempo de exposição ou concentrações mais severas destes ácidos (CAMARGO et al., 2001).

A seleção de genitores e a caracterização da variabilidade genética existente são decisivas para o incremento de eficiência em programas de melhoramento, pois uma das principais necessidades 
do melhorista é a identificação de plantas que possuam genes responsáveis por determinada característica de interesse (BRAMMER, 2002) como tolerância a ácidos orgânicos.

A caracterização de variabilidade genética têm sido desenvolvida em três ambientes: i) em condições de campo; ii) em casa de vegetação, sob condições semi-controladas e iii) em laboratório, com o uso de soluções nutritivas em condições ambientais controladas. Enquanto a avaliação de genótipos em ambientes artificiais não leva em consideração as reais pressões do meio, a seleção em ensaios de campo reúne grande número de variáveis não controladas, tais como tolerâncias diferenciais a estresses climáticos, bióticos ou nutricionais (DUNCAN; BALIGAR, 1990). No caso de gramíneas cultivadas, trabalhos mostram correlações significativas entre parâmetros obtidos em testes de campo e em ambientes artificiais, com solo ou solução nutritiva (HAWTIN; IWANAGA; HODGKIN, 1996). Assim, uma maneira eficiente de avaliação de genótipos para tolerância a ácidos orgânicos em meio de cultivo pode ser realizada em sistemas de hidroponia sob condições controladas.

Kopp et al. (2007b) identificaram variabilidade genética para tolerância a ácidos orgânicos em aveia, no entanto para arroz ainda não existe descrita variabilidade passível de utilização pelos programas de melhoramento. A identificação de genótipos tolerantes a estresse abiótico se torna importante para estudos de variabilidade genética, função, regulação e ação gênica, devido às novas tecnologias (SREENIVASULU; SOPORY; KAVI KISHOR, 2007), além de serem utilizados na incorporação de genes em cultivares superiores por métodos de recombinação ou transformação (KAHL; LAVI, 2001).

A incorporação de genes responsáveis pela tolerância aos ácidos orgânicos em cultivares de alta produtividade, poderá contribuir para o incremento da área cultivada no sistema de semeadura direta de arroz irrigado, e conseqüentemente, aumentar a produtividade, reduzindo os impactos ambientais do cultivo convencional e os custos de produção do cereal.

Os objetivos deste trabalho foram avaliar o desenvolvimento de genótipos de arroz submetidos à ação fitotóxica dos ácidos acético, propiônico e butírico; determinar a variável mais responsiva a fitotoxidez nas plântulas e identificar variabilidade genética para o caráter tolerância aos ácidos em arroz.

\section{Material e Métodos}

O trabalho foi realizado no Laboratório de Dihaplóides e Hidroponia do Centro de Genômica e Fitomelhoramento (CGF) da Faculdade de Agronomia Eliseu Maciel da Universidade Federal de Pelotas (UFPel), localizado no município de Pelotas - RS. Foram utilizados 20 genótipos de arroz os quais foram submetidos a 4 doses de ácidos orgânicos. Os genótipos utilizados pertencem a coleção de trabalho do Banco de Germoplasma de Arroz do CGF/UFPel. Foram utilizadas cultivares das subespécies indica e japonica, e dos sistemas de cultivo irrigado e sequeiro e de diversas origens de lançamento (Tabela 1).

O experimento foi conduzido em sistema hidropônico segundo metodologia descrita por Kopp et al. (2007a) e Kopp et al. (2010) onde foram utilizados potes com capacidade de 5,5 L nos quais foi adaptada uma tela de náilon a tampa de cada pote permitindo a sustentação das plântulas e o crescimento do sistema radicular para o meio de cultivo. Os potes permaneceram em tanque tipo "banho-maria" com temperatura de $25 \pm 1{ }^{\circ} \mathrm{C}$, aeração da solução nutritiva para suprimento de oxigênio, permitindo o desenvolvimento do sistema radicular e iluminação artificial controlada (160 $\mu \mathrm{mol} \mathrm{m} \mathrm{m}^{-2} \mathrm{~s}^{-1}$, fotoperíodo de 14 horas). 
Tabela 1. Relação das cultivares, grupo e sistema de cultivo dos acessos utilizados no estudo de tolerância à toxicidade por ácidos orgânicos.

\begin{tabular}{lccc}
\hline $\mathbf{N}^{\circ}$ & Genótipo & Subespécie & Sistema cultivo \\
\hline 1 & IAC -47 & Indica & Sequeiro \\
2 & Oryzica & Indica & Irrigado \\
3 & Caloro & Indica & Irrigado \\
4 & BRS - Pelota & Indica & Irrigado \\
5 & Yonaochi & Japonica & Sequeiro \\
6 & Supremo - 1 & Indica & Irrigado \\
7 & Fanny & Indica & Sequeiro \\
8 & IAS - Formosa & Indica & Sequeiro \\
9 & Lemont & Indica & Irrigado \\
10 & CICA - 8 & Indica & Irrigado \\
11 & Mazs & Indica & Irrigado \\
12 & Gbegbbete & Japonica & Sequeiro \\
13 & Guichow & Japonica & Irrigado \\
14 & IR - 39379 & Indica & Irrigado \\
15 & Gose Yonkoku & Japonica & Sequeiro \\
16 & Dawn & Japonica & Irrigado \\
17 & BR-IRGA-420 & Indica & Irrigado \\
18 & BRS 6-Chui & Indica & Irrigado \\
19 & Toride - 1 & Indica & Irrigado \\
20 & BRS 7-Taim & Indica & Irrigado \\
\hline
\end{tabular}

Fonte: Elaboração dos autores.

A concentração da solução nutritiva utilizada foi: Nitrato de cálcio $-\mathrm{Ca}\left(\mathrm{NO}_{3}\right)_{2} 4 \mathrm{mM}$, Sulfato de magnésio - $\mathrm{MgSO}_{4} 2 \mathrm{mM}$, Nitrato de potássio - $\mathrm{KNO}_{3} 4 \mathrm{mM}$, Sulfato de amônio - $(\mathrm{NH} 4)_{2} \mathrm{SO}_{4}$ $0,435 \mathrm{mM}$, Potássio fosfato $-\mathrm{KH}_{2} \mathrm{PO}_{4} 0,5 \mathrm{mM}$, Acido bórico $-\mathrm{H}_{3} \mathrm{BO}_{3} 10 \mu \mathrm{M}$, Molibdato de sódio - $\mathrm{NaMoO}_{4}$ 0,10 $\mu \mathrm{M}$, Cloreto de sódio - NaCl 30 $\mu \mathrm{M}$, Sulfato de zinco $-\mathrm{ZnSO}_{4} 0,8 \mu \mathrm{M}$, Sulfato de cobre - $\mathrm{CuSO}_{4} 0,3 \mu \mathrm{M}$, Sulfato de manganês $\mathrm{MnSO}_{4} 2 \mathrm{mM}$, Ferro EDTA - Fe $\mathrm{SO}_{4}+\mathrm{Na} 10 \mu \mathrm{M}$ (CAMARGO; OLIVEIRA, 1981; KOPP et al., 2010).

Para constituição das parcelas experimentais, 180 sementes de cada cultivar foram desinfetadas com hipoclorito de sódio $10 \%$ e postas para germinação a $25 \pm 1{ }^{\circ} \mathrm{C}$ por 72 horas em papel filtro embebido em água, das quais foram selecionadas 120 com comprimento de raiz de $5 \mathrm{~mm}$ e uniformes para constituir o experimento.
Os tratamentos foram constituídos por quatro concentrações da mistura dos ácidos acético, propiônico e butírico na relação de 6:3:1 respectivamente. As concentrações utilizadas foram 0 (testemunha); 3; 6 e $9 \mathrm{mM}$. O pH foi ajustado para 4,7 com $\mathrm{HCl} 1 \mathrm{~N}$ ou $\mathrm{NaOH} 1 \mathrm{~N}$, e monitorado diariamente, pois segundo Rao e Mikkelsen (1977a) e Kopp et al. (2007c) o pH da solução nutritiva em experimentos com ácidos orgânicos é variável e interfere na toxicidade dos ácidos. As doses utilizadas para constituir o experimento foram previamente selecionadas com base nos estudos de Rao e Mikkelsen (1977b), Camargo, Santos e Rossielo (1993), Sousa e Bortolon (2002) e Kopp et al. (2007a) de modo que as reduções relativas no desenvolvimento radicular fossem em torno de $50 \%$ na dose mais elevada. Pode ser observado que de maneira geral os resultados concordam com os trabalhos supra citados, no entanto, existem genótipos com reduções superiores a 50\% no crescimento de raízes e genótipos com praticamente nenhuma redução no comprimento radicular.

Aunidade experimental consistiu de dez sementes para cada repetição. Após realização do sorteio, as unidades experimentais foram alocadas nas telas de náilon adaptadas às tampas dos recipientes de solução hidropônica contendo os tratamentos.

As plântulas permaneceram em solução nutritiva adicionada aos tratamentos por 14 dias. Após esse período elas foram retiradas da tela de náilon e avaliadas quanto aos seguintes caracteres: comprimento de raiz (CR) e parte aérea (CPA) expresso em cm; número de raízes (NR); massa seca de raízes (MSR) e de parte aérea (MSPA) expresso em mg (pesadas após secagem até peso constante em estufa com circulação de ar a $60^{\circ} \mathrm{C}$ ).

Os dados relativos às variáveis mensuradas foram submetidos à análise de variância em um modelo fatorial $(4 \times 20)$, considerando dose e genótipo como fatores fixos. Os efeitos da interação entre estes fatores foram testados na análise de regressão linear, pela significância dos distintos 
graus do polinômio em função dos diferentes níveis do fator dose (quantitativo), sendo apresentados na forma de gráficos individuais para cada genótipo. Também foi executado teste de correlação simples de Pearson entre as variáveis mensuradas. Todas as análises foram realizadas com o software estatístico SAS (STATISTICALANALYSIS SYSTEM, 2002).

\section{Resultados e Discussão}

Os resultados da análise de variância (Tabela 2) demonstraram efeitos significativos para dose, em todas as variáveis mensuradas, efeito de genótipo para as variáveis CR, CPA e NR e interação (dose $\mathrm{x}$ genótipo), apenas para as variáveis CR e CPA.

Tabela 2. Resumo da análise de variância, médias e coeficiente de variação (C.V.) para as variáveis comprimento de raiz (CR) e de parte aérea (CPA), número de raízes (NR), matéria seca de raiz (MSR) e de parte aérea (MSPA) de 20 cultivares de arroz, avaliadas em solução nutritiva com 4 concentrações dos ácidos acético, propiônico e butírico.

\begin{tabular}{lcccccc}
\hline \multirow{2}{*}{ F.V. } & \multirow{2}{*}{ G.L. } & \multicolumn{5}{c}{ Quadrados Médios } \\
\cline { 3 - 6 } & & CR & CPA & NR & MSR & MSPA \\
\hline Genótipo & 19 & $5,39323 *$ & $26,45225^{*}$ & $4,14069^{*}$ & 0,01176 & 0,04526 \\
Doses & 3 & $303,5334^{*}$ & $237,8707^{*}$ & $48,64856^{*}$ & $53,06299 *$ & $136,2333^{*}$ \\
Interação & 57 & $3,07240 *$ & $3,75094 *$ & 0,61302 & 0,00203 & 0,00426 \\
Resíduo & 158 & 1,42742 & 2,65198 & 0,55971 & 0,30151 & 0,58542 \\
\hline Média & & 9,47 & 19,61 & 5,25 & 4,33 & 8,45 \\
C.V. & & 12,61 & 8,30 & 14,26 & 12,70 & 9,06 \\
\hline
\end{tabular}

* Significativo ao nível de $5 \%$ de probabilidade de erro pelo teste $\mathrm{F}$.

Fonte: Elaboração dos autores.

Estas respostas diferenciais em relação ao crescimento de raízes (CR) e parte aérea (CPA) frente as variações crescentes de concentrações de ácidos orgânicos ao qual estão submetidos os genótipos indicam haver variabilidade genética quanto a insensibilidade a estes ácidos. $\mathrm{O}$ fato de ter sido constatada também significância para a fonte de variação "genótipo" demonstra que existe também diferenças em relação à magnitude média destas variáveis para cada genótipo independente da sua resposta. Assim, os genótipos descritos como tolerantes neste trabalho foram aqueles que se demonstraram insensíveis a toxicidade por ácidos orgânicos, mesmo que suas médias não tenham sido elevadas. Estes genótipos foram assim escolhidos em virtude da maior possibilidade de possuírem genes responsáveis pela manutenção da capacidade celular em manter o crescimento de raízes (CR) e parte aérea (CPA) mediante a presença do elemento tóxico.

A análise prosseguiu de modo a verificar a variação nas variáveis CR e CPA dos genótipos nos diferentes níveis de ácidos orgânicos empregados, utilizando análise de regressão, sendo então fixado o fator genótipo. Para as duas variáveis, com a aplicação das equações de regressão linear, foram obtidos os parâmetros até o terceiro grau do polinômio, representados pelos valores de quadrado médio e a respectiva significância do polinômio na Tabela 3. 
Tabela 3. Resumo da análise de variância do modelo de regressão para as variáveis comprimento de raiz (CR) e de parte aérea (CPA) de 20 cultivares de arroz, avaliadas em solução nutritiva com 4 concentrações dos ácidos acético, propiônico e butírico.

\begin{tabular}{|c|c|c|c|c|c|c|}
\hline \multirow{4}{*}{ Genótipo } & \multicolumn{6}{|c|}{ Quadrado Médio } \\
\hline & \multicolumn{3}{|c|}{ CR } & \multicolumn{3}{|c|}{ CPA } \\
\hline & \multicolumn{3}{|c|}{ Grau do Polinômio } & \multicolumn{3}{|c|}{ Grau do Polinômio } \\
\hline & Linear & Quadrática & Cúbica & Linear & Quadrática & Cúbica \\
\hline IAC -47 & $146.672 *$ & 3.102 & 0.176 & $34.752 *$ & 0.961 & 0.093 \\
\hline Oryzica & $47.470 *$ & 2.351 & 0.254 & $28.321 *$ & 0.175 & 0.018 \\
\hline Caloro & $76.614^{*}$ & $13.670^{*}$ & 0.926 & $23.358 *$ & 0.059 & 0.125 \\
\hline BRS - Pelota & $57.991 *$ & 2.017 & 1.021 & $27.701 *$ & 0.108 & 0.060 \\
\hline Yonaochi & $48.461 *$ & $10.000 *$ & 0.534 & 2.077 & 0.014 & 0.017 \\
\hline Supremo - 1 & $55.539 *$ & 5.486 & 1.324 & $26.991 *$ & 0.141 & $0.72 \mathrm{E}^{-3}$ \\
\hline Fanny & $55.639 *$ & $6.391^{*}$ & 0.824 & $34.256^{*}$ & 0.527 & $2.95 \mathrm{E}^{-3}$ \\
\hline IAS - Formosa & $63.882 *$ & $8.604^{*}$ & 0.737 & $44.853^{*}$ & 0.917 & 1.839 \\
\hline Lemont & $12.362 *$ & 0.186 & $5.176^{*}$ & $36.679 *$ & 0.500 & 0.542 \\
\hline $\mathrm{CICA}-8$ & $35.426^{*}$ & $7.263^{*}$ & $0.13 \mathrm{E}^{-3}$ & $42.731^{*}$ & 2.257 & 0.068 \\
\hline Mazs & $87.636^{*}$ & $16.725^{*}$ & 0.201 & $34.041 *$ & 1.005 & $0.66 \mathrm{E}^{-5}$ \\
\hline Gbegbbete & $18.360^{*}$ & 0.549 & 2.431 & 10.174 & 0.870 & $5.00 \mathrm{E}^{-5}$ \\
\hline Guichow & $33.031 *$ & $20.424^{*}$ & 1.246 & $79.626^{*}$ & $11.544^{*}$ & 6.660 \\
\hline IR - 39379 & $50.478^{*}$ & $14.804 *$ & 0.684 & $72.469 *$ & $11.691 *$ & 4.262 \\
\hline Gose Yonkoku & $26.925^{*}$ & 1.958 & 0.941 & 1.579 & 0.055 & 0.013 \\
\hline Dawn & 1.560 & $3.84 \mathrm{E}^{-5}$ & 0.025 & $251.864 *$ & 0.219 & 0.101 \\
\hline BR-IRGA-420 & $46.400 *$ & 3.134 & 1.385 & $26.631 *$ & $0.37 \mathrm{E}^{-3}$ & 0.136 \\
\hline BRS 6 - Chui & $49.149 *$ & $9.615^{*}$ & 0.204 & $36.234^{*}$ & 0.556 & 0.020 \\
\hline Toride -1 & 4.011 & $3.01 \mathrm{E}^{-3}$ & 0.665 & $31.349^{*}$ & 0.333 & 0.012 \\
\hline BRS 7 - Taim & $21.259^{*}$ & 1.474 & 0.351 & $34.438^{*}$ & 1.326 & 0.053 \\
\hline
\end{tabular}

* Significativo ao nível de 5\% de probabilidade de erro pelo teste F.

Fonte: Elaboração dos autores.

As equações de regressão com o devido ajuste do coeficiente de determinação $\left(\mathrm{R}^{2}\right)$ estão apresentadas nas Figuras 1 e 2 para as variáveis comprimento de raízes e parte aérea respectivamente. Ao analisar o comportamento dos genótipos frente ao crescimento de raizes (Figura 1), pode ser verificado que o genótipo Lemont obteve melhor ajuste de regressão polinomial cúbica indicando haver uma estabilidade inicial no crescimento radicular, até a dose de $3 \mathrm{mM}$, seguida de redução significativa entre as doses de 3 e $6 \mathrm{mM}$, estabilizando novamente seu crescimento em valores reduzidos de ácidos entre as doses de 6 e $9 \mathrm{mM}$. Biologicamente este resultado pode ser interpretado como pressupondo que doses menores que $3 \mathrm{mM}$ não são suficientes em causar dano ao desenvolvimento celular e doses entre 6 e $9 \mathrm{mM}$ proporcionam uma atividade minima e constante de desenvolvimento celular das raízes, que no caso deste genótipo foi de aproximadamente $9 \mathrm{~cm}$. Os genótipos Caloro, Yonaochi, Fanny, IAS-Formosa, CICA-8, Mazs, Guichow, IR-39379 e BRS 6-Chui, apresentaram ajuste quadrático em resposta as doses de ácidos. Nestes casos observa-se que para doses reduzidas de ácidos orgânicos ocorre menor decréscimo no comprimento de raízes, com elevada redução nas doses mais elevadas principalmente a partir de $6 \mathrm{mM}$ dos ácidos. Os genótipos que apresentaram ajuste linear foram IAC-47, Oryzica, BRS-Pelota, Supremo 1, Gbegbbete, Gose Yonkoku, BR IRGA 420 e BRS 7 Taim. Para estes casos, pode ser constatado que as reduções no crescimento de raízes foram constantes para as faixas de doses utilizadas no trabalho. 
Para a variável comprimento de parte aérea (Figura 2), os genótipos Guichow e IR-39379 apresentaram ajuste quadrático e, demonstraram que a maior redução no crescimento de parte aérea ocorreu em doses mais elevadas, com praticamente nenhuma redução entre as doses de 0 e $6 \mathrm{mM}$. Já os genótipos IAC-47, Oryzica, Caloro, BRSPelota, Supremo-1, Fanny, IAS-Formosa, Lemont, CICA-8, Mazs, Dawn, BR IRGA-420, BRS6-Chui, Toride-1 e BRS 7 Taim apresentaram regressão linear, igualmente com variação significativa, porém nestes casos com variações constantes para as três doses (3; 6 e 9 mM) utilizadas no experimento.

Como ainda não existe na literatura a descrição de níveis de redução para considerar um genótipo tolerante, ou mesmo, não existem ainda descritos genótipos já classificados como tolerantes ou sensíveis para serem utilizados como testemunhas, foram considerados tolerantes os genótipos que se demonstraram insensíveis as concentrações utilizadas, ou seja, aqueles cujas médias não alteraram significativamente com a elevação das doses utilizadas.

Os dados apresentados na Figura 1 indicam que para a variável comprimento de raízes, os genótipos Dawn e Toride 1 não apresentaram variação significativa quando submetidos aos níveis de tratamento utilizados. Os dados demonstram que até a concentração de $9 \mathrm{mM}$ da mistura dos ácidos utilizados, estes genótipos mantem seu nível de crescimento radicular constante com médias de 10,31 e $9,09 \mathrm{~cm}$ respectivamente.

Para comprimento de parte aérea, foi determinado outro grupo de genótipos com tolerância as concentrações de ácidos orgânicos. Para esta variável, os genótipos Yonaochi, Gbegbbete e Gose Yonkoku foram os que apresentaram insensibilidade a toxidez por ácidos orgânicos, com médias de 23,92; 20,21 e 18,83 cm respectivamente.

Cabe reinterar que os genótipos citados como tolerantes, não necessariamente apresentam elevado potencial no desenvolvimento destas variáveis, mas sim, elevada capacidade em manter seu patamar genético de crescimento. Armstrong e Armstrong (2001) estudando o efeito dos ácidos orgânicos em arroz relataram que os ácidos causam principalmente degradação das membranas celulares e perda do conteúdo celular para o meio. Estes autores relatam ainda que plantas tolerantes devem possuir genes que confiram maior capacidade de formação de membranas celulares que tolerem estes ácidos. Ao se realizar uma análise nas Figuras 1 e 2, pode ser constatado que, para ambas variáveis, os genótipos tolerantes, não necessariamente são também os genótipos com maior potencial em crescimento. Assim, com exceção do genótipo Yonaochi, são genótipos com capacidade limitada de crescimento de raízes e parte aérea, mas que possivelmente possuem genes que mantém a viabilidade celular pela manutenção de suas membranas, garantindo a estabilidade de crescimento frente a ação das doses de ácidos.

Este fato pode ser constatado analisando os valores de intercepto de cada genótipo, onde se percebe grande variabilidade genética para crescimento radicular na ausência de ácidos orgânicos na solução hidroponica (dose $0 \mathrm{mM}$ ). Os valores de crescimento radicular na ausência de ácidos varia entre valores de 9,09 cm (genótipo Toride 1) até $14,82 \mathrm{~cm}$ (genótipo IAC-47), o genótipo com menor crescimento de raízes na ausência de ácidos orgânicos (Toride 1) é tambem um dos que se demonstrou insensível ao efeito fitotoxico dos ácidos. Já para a variável comprimento de parte aérea, verifica-se que ocorre uma menor variação proporcional, com $18,83 \mathrm{~cm}$ para o genótipo Gose Yonkoku e 25,13 cm para o genótipo Dawn. Neste caso, nota-se também que o genótipo com menor crescimento de raízes na ausência de ácidos orgânicos (Gose Yonkoku) é também um dos que se demonstrou insensível ao efeito fitotoxico dos ácidos. 
Figura 1. Representação gráfica, ajuste das equações de regressão e coeficientes de determinação $\left(\mathrm{R}^{2}\right)$ da variável comprimento de raízes das 20 cultivares de arroz, avaliadas em solução nutritiva com 4 concentrações dos ácidos acético, propiônico e butírico.
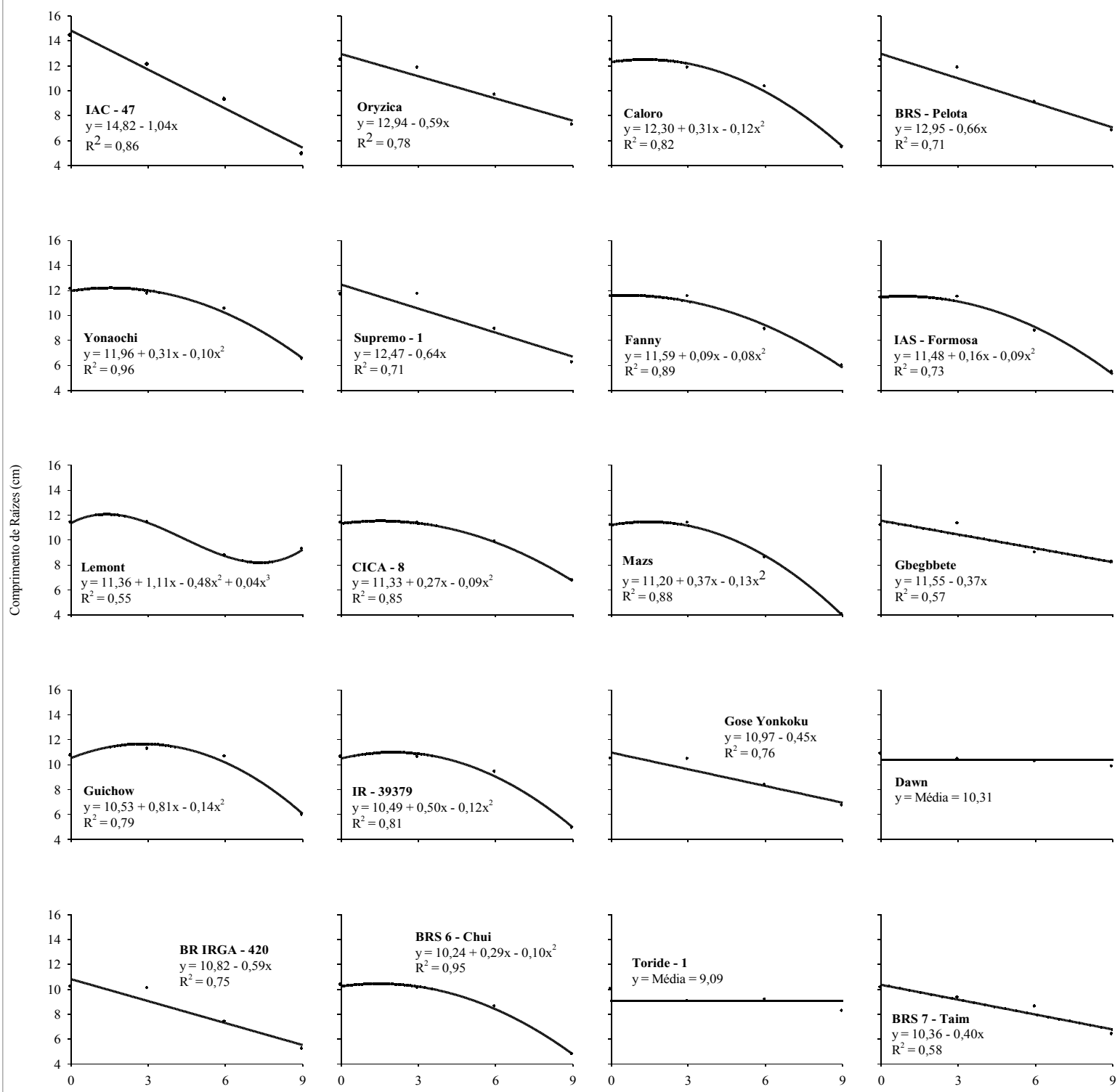

Doses (mM)

Fonte: Elaboração dos autores. 
Figura 2. Representação gráfica, ajuste das equações de regressão e coeficientes de determinação $\left(\mathrm{R}^{2}\right)$ da variável comprimento de parte aérea das 20 cultivares de arroz, avaliadas em solução nutritiva com 4 concentrações dos ácidos acético, propiônico e butírico.
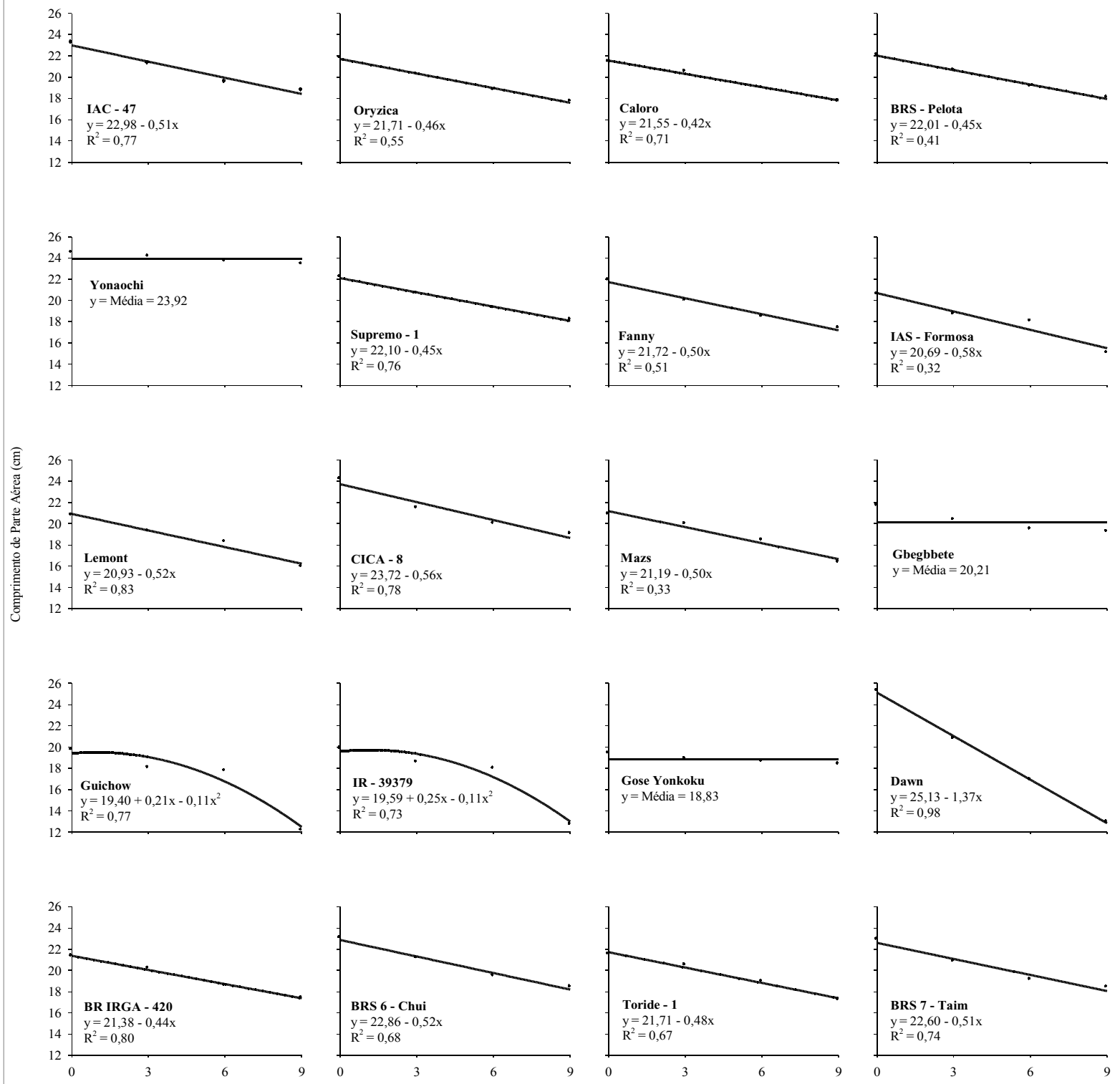

Doses (mM)

Fonte: Elaboração dos autores. 
Os resultados médios obtidos demonstram uma redução em torno de 44,5\% no comprimento radicular e $24,5 \%$ no comprimento de parte aérea quando avaliados todos genótipos na dose de $9 \mathrm{mM}$. Rao e Mikkelsen (1977b) em estudo similar, porém trabalhando com os ácidos isoladamente e na dose de $10 \mathrm{mM}$, relataram reduções no comprimento radicular de 29,7; 43,2 e 45,0\% e no comprimento de parte aérea de 4,6; 20,6 e 34,4\% para os ácidos acético, propiônico e butírico, respectivamente. Interpolando os valores do trabalho de Rao e Mikkelsen (1977b) e comparando com os resultados obtidos neste trabalho, pode se constatar maior toxicidade quando os ácidos são adicionados conjuntamente aos tratamentos. No entanto, futuros estudos poderão comprovar de maneira mais efetiva este efeito sinérgico entre os ácidos utilizados.

Segundo Armstrong e Armstrong (2001) a variável mais afetada pelo efeito dos ácidos orgânicos em arroz é o comprimento radicular, uma vez que o efeito fisiológico responsável pela toxicidade se caracteriza pelo rompimento das membranas do sistema radicular e extravasamento do conteúdo celular onde os ácidos estão em contato direto com os tecidos. A seleção de genótipos para determinados caracteres pode ser feita indiretamente pela análise de variáveis de mais fácil mensuração e que apresentem correlações significativas (BENIN et al., 2003). Assim, se existir correlação significativa entre crescimento radicular e outra variável que apresente variação significativa, seria possível a identificação de genótipos tolerantes mediante a utilização de mais de uma variável simultaneamente sem prejuizo no resultado da análise.

A análise da correlação simples de Pearson (Tabela 4) demonstrou que todas as variáveis analisadas apresentaram correlações significativas entre si. A variável NR apresentou correlação negativa com todas as outras variáveis analisadas, pois está variável foi a única que sofreu acréscimos no seu desempenho relativo frente ao estresse. Apesar destas correlações com a variável NR serem significativas, suas magnitudes são muito inferiores quando comparadas as demais correlações apresentadas. As variáveis CR, CPA, MSR e MSPA apresentaram correlações positivas e significativas entre si, demonstrando terem o mesmo comportamento generalizado, ou seja, reduções nos valores médios de uma variável são acompanhadas de reduções similares nas demais variáveis correlacionadas no grupo dos 20 genótipos estudados. Assim, além das variáveis CR e CPA, as demais podem ser utilizadas simultaneamente na análise pois apresentam variação significativa para a fonte de variação "dose" e correlação significativa com as variáveis que apresentam interação (dose $\mathrm{x}$ genótipo) significativa. No entanto não deve ser descartada a possibilidade de seleção baseada em aviações independentes entre cada variável, pois podem ocorrer mecanismos genéticos diferenciais responsáveis pela tolerância de genótipos frente ao estresses abióticos (YANG; YOUNG-YELL; JIYOUNG, 2000).

Tabela 4. Coeficientes de correlação de Pearson entre as variáveis comprimento de raiz (CR) e parte aérea (CPA), número de raízes (NR) e matéria seca de raiz (MSR) e parte aérea (MSPA), de 20 cultivares de arroz, avaliadas em solução nutritiva com 4 concentrações dos ácidos acético, propiônico e butírico.

\begin{tabular}{lccccc}
\hline & CR & CPA & NR & MSR & MSPA \\
\hline CR & & $0,48^{*}$ & $-0,46^{*}$ & $0,82^{*}$ & $0,69^{*}$ \\
CPA & & & $-0,26^{*}$ & $0,53^{*}$ & $0,72^{*}$ \\
NR & & & & $-0,54^{*}$ & $-0,53^{*}$ \\
MSR & & & & & $0,77^{*}$ \\
MSPA & & & & \\
\hline
\end{tabular}

* Significativo ao nível de 5\% de probabilidade de erro pelo teste t.

Fonte: Elaboração dos autores.

Associando os resultados dos genótipos tolerantes com as suas descrições apresentadas na Tabela 1 pode ser constatado que um genótipo da subespécie índica e um japonica apresentaram estabilidade no crescimento radicular, já quando avaliado o crescimento de parte aérea, os três genótipos tolerantes pertencem a subespécie japonica. Porém, 
outro fato que pode ser comprovado, é que todos os genótipos com elevada capacidade de crescimento radicular frente ao estresse pertencem ao sistema de cultivo de irrigação por inundação. Provavelmente o processo de melhoramento de genótipos sob sistema de inundação propiciou um ambiente com maiores concentrações de ácidos orgânicos, e desta maneira, uma seleção indireta para o caráter pode ter sido decisiva para que um maior número de genótipos tolerantes fosse evidenciado dentro deste grupo de cultivares.

Armstrong e Armstrong (2001) estudando o efeito dos ácidos orgânicos em arroz relataram que plantas tolerantes devem possuir genes que confiram maior capacidade de formação de membranas celulares que tolerem estes ácidos. Assim os genótipos da subespécie japonica descritos como tolerantes, ainda que, pertençam ao sistema de cultivo de sequeiro são acessos de coleções nucleares de germoplasma com elevada rusticidade. Em geral os genótipos de maior rusticidade são tolerantes a muitos tipos de estresse bióticos e abióticos em virtude principalmente de sua capacidade diferencial na constituição e formação do sistema membranário (HINCHA; HAGEMANN, 2004). Estes genótipos da subespécie japonica, podem ser utilizados pelos programas de melhoramento na forma de cruzamentos com cultivares de elevada produtividade e valor comercial. Porém, o cruzamento entre estes dois grupos geralmente acarreta em recombinações insatisfatórias ao ideótipo focado nos programas de melhoramento de arroz no Brasil, principalmente no que diz respeito à qualidade de grãos (MAGALHÃES JUNIOR et al., 2004). No entanto podem ser de grande valia na obtenção de populações para estudos genéticos de mapeamento ou de expressão gênica.

A utilização dos genótipos tolerantes ao efeito fitotóxico dos ácidos orgânicos em programas de melhoramento poderá contribuir de maneira substancial no desenvolvimento de cultivares com maior germinação e estabelecimento inicial de plântulas na lavoura de arroz irrigado sob plantio direto ou cultivo mínimo. Isto reduziria significativamente os custos de produção e danos ambientais advindos do sistema de semeadura convencional de arroz, bem como aumentaria a produtividade final do cereal consideravelmente.

\section{Conclusões}

Doses de até $9 \mathrm{mM}$ da mistura dos ácidos acético, propiônico e butírico na relação de 6:3:1, respectivamente causam reduções significativas nas variáveis comprimento de raiz e parte aérea; massa seca de raízes e de parte aérea e aumento significativo no número de raízes sendo indicada para estudos de variabilidade genética em arroz.

Existe variabilidade genética para crescimento radicular e de parte aérea nos genótipos de arroz estudados sob efeito fitotóxico dos ácidos orgânicos.

As cultivares Dawn e Toride 1 apresentam estabilidade no crescimento de raízes e as cultivares Yonaochi, Gbegbbete e Gose Yonkoku apresentam estabilidade no crescimento de parte aérea quando submetidas a níveis crescentes de ácidos orgânicos.

Genótiposdasubespéciejaponica edesenvolvidos para cultivo em sistema de irrigação por inundação obtem melhor desempenho no crescimento de raízes e de parte aérea quando submetidos ao estresse por ácidos orgânicos.

\section{Referências}

ANGELES, O. R.; JOHNSON, S. E.; BURESH, R. J. Soil solution sampling for organic acids in rice paddy soils. Soil Society of American Journal, Madison, v. 70, n. 1, p. 48-70, 2005.

ARMSTRONG, J.; ARMSTRONG, W. Rice and Phragmites: effects of organic acids on growth, root permeability, and radial oxygen loss to the rhizosphere. American Journal of Botany, Louis, v. 88, n. 8, p. 13591370, 2001.

BENIN, G.; CARVALHO, F. I. F.; OLIVEIRA, A. C.; ASSMANN, I. C.; FLOSS, E. L.; LORENCETTI, C.; MARCHIORO, V. S.; SILVA, J. G. Implicações do ambiente sobre o rendimento e suas influências sobre 
estimativas de parâmetros genéticos. Revista Brasileira de Agrociência, Pelotas, v. 9, n. 3, p. 207-214, 2003.

BOHNEN, H.; SILVA, L. S.; MACEDO, V. R. M.; MARCOLIN, E. Ácidos orgânicos na solução de um gleissolo sob diferentes sistemas de cultivo com arroz irrigado. Revista Brasileira de Ciência do Solo, Viçosa, v. 29, n. 3, p. 475-480, 2005.

BRAMMER, S. P. Variabilidade e diversidade genética vegetal: requisito fundamental em um programa de melhoramento. Passo Fundo: Embrapa Trigo, 2002. 9 p. (Série Documentos, 29).

CAMARGO, de O. C. E.; OLIVEIRA, O. F. Tolerância de cultivares de trigo a diferentes níveis de alumínio em solução nutritiva e no solo. Bragantia, Campinas, v. 49, n. 1, p. 21-23, 1981.

CAMARGO, F. A.; SANTOS, G. de A.; ROSSIELO, R. O. P. Efeito dos ácidos acético e butírico sobre o crescimento de plântulas de arroz. Pesquisa Agropecuária Brasileira, Brasília, v. 28, n. 9, p. 1011-1018, 1993.

CAMARGO, F. A.; ZONTA, E.; SANTOS, G. de A.; ROSSIELO, R. O. P. Aspectos fisiológicos e caracterização de toxidez a ácidos orgânicos voláteis em plantas. Ciência Rural, Santa Maria, v. 31, n. 3, p. 523529, 2001.

COMPANHIA NACIONAL DE ABASTECIMENTO CONAB. Acompanhamento de safra brasileira: grãos, quarto levantamento, janeiro 2011. Companhia Nacional de Abastecimento. Brasília: Conab, 2011.

DEVOS, K. M.; GALE, M. D. Genome relationships: the grass model in current research. Plant Cell, Rockville, v. 12, n. 5, p. 637-646, 2000.

DUNCAN, R. R.; BALIGAR, V. C. Genetics, breeding, and physiological mechanisms of nutrient uptake and use efficiency: an overview. In: BALIGAR, V. C.; DUNCAN, R. R. (Ed.). Crops as enhancers of nutrient use. San Diego: Academic Press, 1990. p. 3-35.

GOMES, A. S.; MAGALHÃES JUNIOR, A. M. Arroz irrigado no sul do Brasil. Brasília: Embrapa-Informação Tecnológica. 2004. 899 p.

GOTOH, S.; ONIKURA, Y. Organic acids in a flooded soil receiving added rice straw and their effect on the growth of rice. Plant Nutrition, Weinheim, v. 17, p. 1-8, 1971.

HAWTIN, G.; IWANAGA, M.; HODGKIN, T. Genetic resources in breeding for adaptation. Euphytica, Dordrecht, v. 92, n. 1-2, p. 255-266, 1996.

HINCHA, D. K.; HAGEMANN, M. Stabilization of model membranes during drying by compatible solutes involved in the stress tolerance of plants and microorganisms. Biochemical Journal, London, v. 383, n. 2, p. 277-283, 2004.

INTERNATIONAL RICE GENOME SEQUENCING PROJECT - IRGSP. The map-based sequence of the rice genome. Nature, London, v. 436, n. 7052, p. 793-800, 2005.

JANICK, J. Plant breeding reviews. New York: J.Wiley, 2001. $336 \mathrm{p}$.

JOHNSON, S. E.; ANGELES, O. R.; BRAR, D. S.; BURESH, R. J. Faster anaerobic decomposition of a brittle straw rice mutant: implications for residue management. Soil Biology \& Biochemistry, Oxford, v. 38, n. 7, p. 1880-1892, 2006.

KAHL, G.; LAVI, U. Mutant germplasm characterisation using molecular markers. Viena: FAO/IAEA, 2001. 77 p.

KOPP, M. M.; COIMBRA, J. L. M.; LUZ, V. K.; SOUSA, R. O.; CARVALHO, F. I. F.; OLIVEIRA, A. C. Organic acid tolerance in $\mathrm{M}_{3}$ families of oat mutants. Crop Breeding and Applied Biotechnology, Viçosa, v. 7, n. 1 , p. $59-66,2007 \mathrm{~b}$.

KOPP, M. M.; LUZ, V. K.; COIMBRA, J. L. M.; SOUSA, R. O.; CARVALHO, F. I. F.; OLIVEIRA, A. C. Níveis críticos dos ácidos acético, propiônico e butírico para estudos de toxicidade em arroz em solução nutritiva. Acta Botanica Brasílica, São Paulo, v. 21, n. 1, p. 147154, 2007a.

KOPP, M. M.; LUZ, V. K.; MAIA, L. C.; COIMBRA, J. L. M.; SOUSA, R. O.; CARVALHO, F. I. F.; OLIVEIRA, A. C. Avaliação de genótipos de arroz sob efeito do ácido butírico. Acta Botanica Brasílica, São Paulo, v. 24, n. 2, p. 578-584, 2010.

KOPP, M. M.; LUZ, V. K.; MAIA, L. C.; SOUSA, R. O.; CARVALHO, F. I. F.; OLIVEIRA, A. C. Rice genotype responses to acetate aiming to improve for no-tillage and minimal-tillage systems. Communications in Soil Science and Plant Analysis, Philadelphia, v. 40, n. 17-18, p. 2773-2783, 2009b.

KOPP, M. M.; LUZ, V. K.; SILVA, V. N.; COIMBRA, J. L. M.; MAIA, L. C.; CARVALHO, F. I. F.; OLIVEIRA, A. C. Efeito do pH da solução nutritiva na fitotoxidez causada por ácidos orgânicos em arroz. Magistra, Cruz das Almas, v. 19, n. 1, p. 40-46, 2007 c.

KOPP, M. M.; LUZ, V. K.; SOUZA, V. Q.; COIMBRA, J. L. M.; SOUSA, R. O.; CARVALHO, F. I. F.; OLIVEIRA, A. C. Methodology adjustments for organic acid tolerance studies in oat under hydroponic systems. Brazilian Archives of Biology and Technology, Curitiba, v. 52, n. 3, p. 531-539, 2009a. 
MAGALHÃES JUNIOR, A. M. de; TERRES, A. L.; FAGUNDES, P. R.; FRANCO, D. F.; ANDRES, A. Aspectos genéticos, morfológicos e de desenvolvimento de plantas de arroz irrigado. In: GOMES, A. da S.; MAGALHÃES JUNIOR, de A. M. (Ed.). Arroz irrigado no sul do Brasil. Brasília, DF: Embrapa Informação Tecnológica, 2004. p. 143-160.

PINTO, L. F. E.; LAUS, J. A.; PAUleTtO, E. A. Solos de várzea no sul do Brasil. In: GOMES, A. da S.; MAGALHÃES JUNIOR, A. M. (Ed.). Arroz irrigado no sul do Brasil. Brasília, DF: Embrapa Informação Tecnológica, 2004. p. 75-95.

PONNAMPERUMA, F. M. The chemistry of submerged soils. Advances in Agronomy, San Diego, v. 24, n. 1, p. 29-96, 1972.

RAO, D. N.; MIKKELSEN, D. S. Effect of acetic, propionic, and butyric acids on young rice seedlings growth. Agronomy Journal, Madison, v. 69, n. 6, p. 923928, 1977a.

. Effect of acetic, propionic, and butyric acids on rice seedlings growth. and nutrition. Plant and Soil, Dordrecht, v. 47, n. 6, p. 323-334, 1977 b.
SOUSA, R. O.; BORTOLON, L. Crescimento radicular e da parte aérea do arroz (Oryza sativa L.) e absorção de nutrientes em solução nutritiva com diferentes concentrações de ácido acético. Revista Brasileira de Agrociência, Pelotas, v. 8, n. 3, p. 231-235, 2002.

SREENIVASULU, N.; SOPORY, S. K.; KAVI KISHOR, P. B. Deciphering the regulatory mechanisms of abiotic stress tolerance in plants by genomic approaches. Gene, Amsterdam, v. 388, n. 1-2, p. 1-13, 2007.

STATISTICAL ANALYSIS SYSTEM - SAS. Statistical analysis system - getting started with the sas learning edition. Cary, NC: SAS Institute, 2002. 86 p.

YANG, G.; YOUNG-YELL, M.; JI-YOUNG, M. Identification of rice varieties with high tolerance or sensitivity to lead and characterization of the mechanism of tolerance. Plant Physiology, Rockville, v. 124, n. 3, p. 1019-1026, 2000. 
